\title{
Strategy for Modulation of Central Dopamine Transmission Based on the Partial Agonist Concept in Schizophrenia Therapy
}

\author{
Atsuko Inoue* and Yoshihiro Nakata \\ Department of Pharmacology, Institute of Pharmaceutical Sciences, Hiroshima University School of Medicine, \\ Kasumi 1-2-3, Minami-ku, Hiroshima 734-8551, Japan
}

Received January 18, 2001

\begin{abstract}
The dopamine system is known to be closely involved in brain neuronal dysfunction and in diseases such as Parkinson's disease, Tourette's syndrome, attention deficit hyperactive disorder, generation of pituitary tumors and schizophrenia. According to the classical dopamine hypothesis on the pathology of schizophrenia, conventional antipsychotics has $\mathrm{D}_{2}$ dopamine receptor antagonistic profiles. However, the use of typical antipsychotics has several limitations; that is, some patients do not respond to them, they can even worsen negative symptoms, and they can provoke unacceptable extrapyramidal and endocrine side effects. To produce effective antipsychotics with reduced side effects, partial agonists to $\mathrm{D}_{2}$ dopamine receptors $\left(\mathrm{D}_{2}\right.$ receptors) have been developed. Despite the effectiveness of partial agonists for pre- and postsynaptic $\mathrm{D}_{2}$ receptors, administration of such drugs results in inconsistent clinical effects to ameliorate the symptoms of schizophrenia. Thus, strategies for obtaining ideal effective antipsychotics with reduced side effects are considered in this short review with respect to the intrinsic efficacies and affinities of the partial agonists, based on the partial agonist concept.
\end{abstract}

Keywords: Dopamine receptor, Antipsychotic, Partial agonist, Intrinsic efficacy, Affinity, Schizophrenia

\section{Introduction}

Schizophrenia is a chronic psychiatric illness with two major types of symptoms, positive symptoms such as hallucinations and delusions and negative symptoms such as amotivation, apathy and asociality. The different types and courses of schizophrenic symptoms indicate a disease caused by multiple neurochemical abnormalities. Although the ultimate causes of schizophrenia remains unknown, since the clinically effective antipsychotics commonly block dopamine receptors (1), it has been thought that schizophrenia is caused by the up-regulated condition of dopamine neuronal activity. Thus, the main property of typical antipsychotics has been the pharmacological antagonism of $D_{2}$-like dopamine receptors ( $D_{2}$-like receptors) (1). However, some patients are considered unresponsive to these typical antipsychotics (2). Especially, in schizophrenia predominantly expressing negative symptoms, a dopamine deficit rather than an excess has been hypothesized. Accordingly, a typical antipsychotic, haloperidol, cannot

*Corresponding author. FAX: +81-82-257-5314

E-mail: ainoue@hiroshima-u.ac.jp ameliorate and can even worsen some symptoms (3) and a nonselective dopamine agonist could be effective. Indirect dopamine agonists like L-dopa or D-amphetamine generally increase the central dopaminergic function, which was reported to have beneficial effects on some negative symptoms in several cases $(4,5)$. Furthermore, typical antipsychotics have serious side effects. For example, they cause extrapyramidal dysfunction inducing Parkinsonian symptoms that would be due to the blockade of $\mathrm{D}_{2}$ dopamine receptors $\left(\mathrm{D}_{2}\right.$ receptors $)$ in the striatum. They also induce hyperprolactinemia through the blockade of $\mathrm{D}_{2}$ receptors in the pituitary. In the search for antipsychotics that are effective against both positive and negative symptoms and have reduced side effects, the following three approaches have been undertaken. Firstly, at least 5 distinct dopamine receptor subtypes $\left(D_{1}-D_{5}\right)$ have been found by molecular biological techniques. Not only the $\mathrm{D}_{2}$ receptors but also some other subtypes are preferentially distributed in the limbic area or frontal cortex of the brain where they might be involved in mental illness either by themselves or by interaction with one another. Some antipsychotics developed recently might possess significant affinities to dopa- 
mine receptor subtypes rather than the $\mathrm{D}_{2}$ receptors. Indeed clozapine, a potentially effective antipsychotic with reduced side effects, shows an approximately tenfold higher affinity to the $\mathrm{D}_{4}$ receptors than the $\mathrm{D}_{2}$ receptors (6). In addition, Lidow et al. speculated that balancing opposing actions through $\mathrm{D}_{1}$ and $\mathrm{D}_{2}$ receptors is the key to optimal drug therapy (7). Secondly, systems other than the dopaminergic system (e.g., glutamatergic, cholinergic, serotonergic, peptidergic and GABAergic systems) could be involved in the pathogenesis of schizophrenia. Clozapine has potent affinity to the $5-\mathrm{HT}_{2 \mathrm{~A}}$ receptors as well as $\mathrm{D}_{4}$ receptors (8), and levels of glutamate receptor subunits are reported to be changed by chronic treatment with antipsychotics (9). Thirdly, this short review describes partial agonists that target the $\mathrm{D}_{2}$ receptors in discrete regions of the CNS with intermediate to high affinities and negligible intrinsic efficacies.

\section{Dopaminergic system in the CNS}

The dopaminergic system in the brain is well known to be associated with cognitive, motive, motor and endocrine functions. There are three major pathways in the brain. One is the nigrostriatal pathway which arises in dopaminesynthesizing neurons of the substantia nigra compacta and projects to the dorsal striatum. This pathway contains as much as $80 \%$ of all the dopamine in the brain with the highest level in the striatum, the area most enriched in nerve terminals. This pathway is involved in the control of movement, and its degeneration causes Parkinsons disease, characterized by tremors, rigidity and akinesia. The other major pathways in the brain are the mesocortical and mesolimbic pathways that arise in the ventral tegmental area and project to the frontal cortex and the limbic areas such as the nucleus accumbens and the olfactory tubercle, which are involved in motivated behavior, and these systems may be the targets of antipsychotics. The tuberoinfundibular pathway arises in cells of the periventricular and arcuate nuclei of the hypothalamus and projects to the intermediate lobe of the pituitary to control the secretion of $\alpha$-melanocyte-stimulating hormone from melanotroph cells and to the median eminence of the hypothalamus where dopamine is released and reaches the anterior pituitary via the portal system to control the secretion of prolactin from lactotroph cells.

Dopamine exerts its multiple actions via specific receptors. To date, at least five dopamine receptor subtypes have been distinguished by molecular cloning techniques, all of which belong to a family of seven transmembrane domain G-protein coupled receptors $(10,11)$. They are grouped as two major subfamilies, $\mathrm{D}_{1}$ - and $\mathrm{D}_{2}$-like receptors, according to structure as assessed from deduced amino acid sequences and their pharmacological profiles such as the similarities of the binding affinities of the ligands. The
$\mathrm{D}_{1}$-like receptor subfamily consists of $\mathrm{D}_{1}$ and $\mathrm{D}_{5}$ receptors and the $\mathrm{D}_{2}$-like receptor subfamily, $\mathrm{D}_{2}, \mathrm{D}_{3}$ and $\mathrm{D}_{4}$ receptors. $\mathrm{D}_{1}$-like receptors are positively linked to adenylyl cyclase, while $\mathrm{D}_{2}$-like receptors are generally negatively linked to this enzyme. In contrast to $\mathrm{D}_{1}$-like receptors, the $\mathrm{D}_{2}$-like receptors have several introns in the coding region of their genes and mRNA isoforms generated by alternative splicings. Two functional isoforms of $\mathrm{D}_{2}$ receptor mRNA, called $D_{2 L}$ and $D_{2 S}$ receptor mRNAs, have been found, the former of which is identified by the existence of 29 amino acids in the putative third intracellular domain compared to the latter isoform $(12,13)$. Although these two isoforms are distributed unevenly through the brain, they have similar pharmacological profiles that are not distinguished by the dopaminergic ligands, and the events that regulate the splicing of the $\mathrm{D}_{2}$ receptor gene are not yet understood.

\section{Autoreceptors as targets of antipsychotics}

The $\mathrm{D}_{2}$ receptors are expressed predominantly in the caudate putamen, nucleus accumbens and olfactory tubercle, and the $\mathrm{D}_{3}$ receptors are expressed in more restricted regions of the brain such as the islands of Calleja, a few septal nuclei, the hypothalamus and a few regions of the thalamus and cerebellum. The mRNAs of both receptors are also expressed in the substantia nigra pars compacta and in the ventral tegmental area, where dopamine neuronal somas project to discrete regions of the brain. These mRNAs disappear on treatment with dopamine neuronal toxin 6hydroxy-dopamine, indicating that the $\mathrm{D}_{2}$ and $\mathrm{D}_{3}$ receptors are located in the dopamine neurons as autoreceptors (14).

Generally, autoreceptors regulate their own neuronal activities by a negative feedback mechanism. Two types of autoreceptors are located in the neuronal cell soma (somatodendritic autoreceptors) and neuronal terminus (pre-synaptic receptors). The former exists in the substantia nigra and the ventral tegmental area and the latter in the striatum, limbic area and cortex in the case of the dopaminergic system. The stimulation of pre-synaptic receptors inhibits the synthesis and release of neurotransmitters, while the stimulation of somatodendritic autoreceptors leads to an inhibition of the neuronal firing rate, which is the case also in the dopaminergic system. Indeed, studies have found that agonists for the $\mathrm{D}_{2}$ or $\mathrm{D}_{3}$ receptors inhibit dopamine release from the nerve terminals (15). The contribution of the $\mathrm{D}_{3}$ receptors to dopamine autoreceptor function, however, might be small because it was reported that $\mathrm{D}_{2}$ receptorsbut not $\mathrm{D}_{3}$ receptors-deficient mice show dopamine autoreceptor dysfunction $(16,17)$.

Consequently, it has been hypothesized that a selective stimulation of the dopamine autoreceptors by autoreceptorselective agonists can decrease the synthesis and release of dopamine and neuronal activity and thus ameliorate the positive symptoms of schizophrenia. While a typical anti- 
psychotic such as haloperidol blocks dopaminergic transmission completely to induce extrapyramidal side effects, an autoreceptor agonist, which merely diminishes the tone of the dopaminergic system is thought to be free from such side effects. Therefore, autoreceptor-selective agonists (pramipexole, roxindole, etc.) that do not interfere with post-synaptic receptors have been developed in the past years. However, administration of autoreceptor-selective agonists such as talipexole, roxindole and pramipexole have yielded clinically inconsistent results and did not result in a significant improvement of positive symptoms (18). Rather, schizophrenic symptoms could be worsened by an autoreceptor agonist because it might also stimulate post-synaptic receptors if it is not completely selective to pre-synaptic autoreceptors alone or if it is used at higher doses. The dopaminergic autoreceptors are the $\mathrm{D}_{2}$ receptors, which are identical to the post-synaptic $\mathrm{D}_{2}$ receptors despite the possibility of a different interaction with the different second messenger systems. As a matter of course, it is thought to be difficult for ligands to distinguish between the autoreceptors and the post-synaptic receptors. The autoreceptor-selective agonist even showed considerable intrinsic activity at denervated and thus supersensitized post-synaptic receptors (19). Furthermore, autoreceptors could be easily down regulated. As reported previously, an autoreceptor non-selective agonist, $n$-propylnorapomorphine, produced antipsychotic effects after acute but not chronic administrations (20). This appears to be a very rapid tolerance to the antipsychotic effects probably due to the down regulation of the dopamine autoreceptors. Since the therapeutic action of antipsychotics takes a longer time to develop, with such a long administration schedule, the predominant antipsychotic effects of the drugs will be post-synaptically rather than pre-synaptically mediated.

\section{Partial agonists as ideal antipsychotics}

A number of dopamine receptor partial agonists have been developed for use as antipsychotics. A partial agonist is a compound that displays a large range of intrinsic activities at the same receptors depending on the conditions and model used during the development of the compound (21). Such a drug displays potent agonistic effects at the presynaptic $D_{2}$ receptors, which have a high receptor reserve (22), whereas at a similar concentration, it fails to display agonism at the post-synaptic $\mathrm{D}_{2}$ receptors, which have virtually no receptor reserve. The intrinsic efficacy of a dopamine-receptor partial agonist depends on the sensitivity and responsiveness of the dopamine receptors influenced by its occupancy. That is to say, a partial agonist may act as a dopamine receptor agonist in the substantia nigra and the ventral tegmental area, where the $\mathrm{D}_{2}$ receptors exist as somatodendritic autoreceptors and the amount of endogenous dopamine is relatively low, and as an antagonist at the post-synaptic $\mathrm{D}_{2}$ receptors in the striatum, the limbic areas and pituitary, where the amount of endogenous dopamine is high. The pre-synaptic dopamine $\mathrm{D}_{2}$ receptors in the latter brain area may have a high receptor reserve for such a drug to act as an agonist. The prototypical drug of this group is preclamol, (-)-3-(3-hydeoxyphenyl)- $N-n$ propyl-piperidine (3-PPP). The rational principle of this approach has been an apparent agonistic effect on the autoreceptors to inhibit dopamine synthesis and release and reduced endocrinal and extrapyramidal side effects because of inactivity for post-synaptic receptors. However, as mentioned above, autoreceptor-selective agonists have inconsistent antipsychotic effects and can even provoke positive symptoms. This is thought to be due to the down regulation of the autoreceptors and the substantial agonistic effects on the post-synaptic receptors. Thus, on repeated administration of antipsychotics, the contribution of postsynaptic receptors rather than autoreceptors should be considerable. It is likely that the intrinsic efficacies of most partial agonists have been too high, and that an ideal antipsychotic should have been weaker or even have negligible intrinsic efficacy at the $\mathrm{D}_{2}$ dopamine receptors.

In this respect, OPC-14597 (aripiprazole), a quinolinone derivative which has been demonstrated to be clinically useful as an antipsychotic drug with reduced extrapyramidal motor and endocrinal side effects, is an interesting recent development. This compound is a congener of OPC4392 but has much less intrinsic efficacy (23).

We found that aripiprazole competed against $\left[{ }^{3} \mathrm{H}\right]$ spiperone binding with 100 -fold more affinity than $\left[{ }^{3} \mathrm{H}\right] \mathrm{SCH} 23390$ binding and inhibited GTPase activities induced by the $\mathrm{D}_{2}$ agonist quinpirole in rat striatum membranes, indicating that this compound exerted high affinity for the post-synaptic $\mathrm{D}_{2}$ receptor antagonist, similar to the conventional antipsychotic haloperidol. Nevertheless, in contrast to haloperidol, the chronic administration of aripiprazole did not increase $\left[{ }^{3} \mathrm{H}\right]$ spiperone binding or the $\mathrm{D}_{2}$ receptor mRNA in rat brain striatum (24). We also investigated the $\mathrm{D}_{2}$ receptors in the rat pituitary. The chronic administration of haloperidol greatly increased $\left[{ }^{3} \mathrm{H}\right]$ spiperone binding and the amount of $\mathrm{D}_{2}$ receptor mRNA, which indicates that the receptors were up-regulated following repeated administration of the antagonist. Aripiprazole, conversely, decreased $\left[{ }^{3} \mathrm{H}\right]$ spiperone binding and $\mathrm{D}_{2}$ receptor mRNA levels in the rat pituitary (25). These results might be reflected in the clinical properties of aripiprazole's effect on schizophreniic symptoms with reduced extrapyramidal and endocrinal side effects.

In spite of the common pharmacological properties of haloperidol and aripiprazole, namely, high affinity postsynaptic antagonism, there are differences in their effects on the $\mathrm{D}_{2}$ receptors in the striatum on chronic treatment. Two distinctive factors are involved. Firstly, haloperidol 
has no intrinsic activity in the $\mathrm{D}_{2}$ receptors in the striatum, while aripiprazole has some intrinsic efficacy. This means that aripiprazole is a partial agonist for the $\mathrm{D}_{2}$ receptors and thus acts as an agonist on autoreceptors and as an antagonist on posy-synaptic $\mathrm{D}_{2}$ receptors. Another group has demonstrated that aripiprazole works as a partial agonist in the rat pituitary (26). Secondly, aripiprazole has adequate affinity for $\mathrm{D}_{2}$ receptors. The $\mathrm{K}_{\mathrm{i}}$ value of aripiprazole was $38 \mathrm{nM}$ for $\left[{ }^{3} \mathrm{H}\right]$ spiperone binding in our assay, which shows a high affinity to the $\mathrm{D}_{2}$ receptors, but somewhat lower than that of haloperidol. Haloperidol has been reported to show $\mathrm{K}_{\mathrm{i}}$ values of $0.6-1.2 \mathrm{nM}$ for $\mathrm{D}_{2}$ receptors. In another study, aripiprazole had a $\mathrm{K}_{\mathrm{i}}$ value of $4.7 \mathrm{nM}$, which is rather mild compared to haloperidol, with a $\mathrm{K}_{\mathrm{i}}$ of $0.41 \mathrm{nM}$ in rat striatal membranes (23).

Figure 1 shows a scheme describing the mode of action of an ideal antipsychotic in the dopaminergic system in the brain. Dopaminergic neuronal systems in the brain have $\mathrm{D}_{2}$ autoreceptors, which are the somatodendritic autoreceptors and the pre-synaptic autoreceptors, and the post-synaptic $\mathrm{D}_{2}$ receptors. The somatodendritic autoreceptors are located in the substantia nigra and ventral tegmental area. The postsynaptic $\mathrm{D}_{2}$ receptors and the pre-synaptic autoreceptors are located in the striatum and the limbic area where dopamine neurons innervate and dopaminergic neuronal terminals exist. The pre-synaptic autoreceptors have a high receptor reserve, in contrast to the post-synaptic receptors. The partial agonist could bind the pre-synaptic autoreceptors to act as a potent agonist. At the somatodendritic autoreceptors, the amount of endogenous dopamine is so low that the partial agonist could bind to act as an agonist. These effects depress the dopaminergic neuronal activity, which may effectively ameliorate the positive symptoms of schizophrenia. However, these autoreceptors are easily down-regulated by repeatedly administering agonists. At the post-synaptic receptors, since significant amounts of endogenous dopamine exist and there is no receptor reserve, partial agonists with low intrinsic efficacy act as an antagonist to provoke the antipsychotic effects. The potency of the intrinsic efficacy of the partial agonist is important because if it is high, it will exacerbate the positive symptoms. Furthermore, the occupancy of the postsynaptic $\mathrm{D}_{2}$ receptors by the partial agonist in the striatum or the limbic area depends on the affinity of the partial agonist. In the striatum, a high level of endogenous dopamine exists. Conventional antipsychotics such as haloperidol with super high affinity to the $\mathrm{D}_{2}$ receptors could block the post-synaptic $\mathrm{D}_{2}$ receptors completely despite the existence of much endogenous dopamine, to induce the extrapyramidal side effects. Partial agonists with a relatively low affinity to the $\mathrm{D}_{2}$ receptors fail to compete for the endogenous dopamine and could not bind the post-synaptic $\mathrm{D}_{2}$ receptors in the striatum. In the limbic area, a low level of endogenous dopamine could allow drugs with a range of affinities to occupy the post-synaptic $\mathrm{D}_{2}$ receptors and exert antipsychotic effects as $\mathrm{D}_{2}$ receptor antagonists because of their low intrinsic activities. Thus, partial agonists with little intrinsic activity and adequate affinity could make for an ideal antipsychotic drug with reduced side effects.

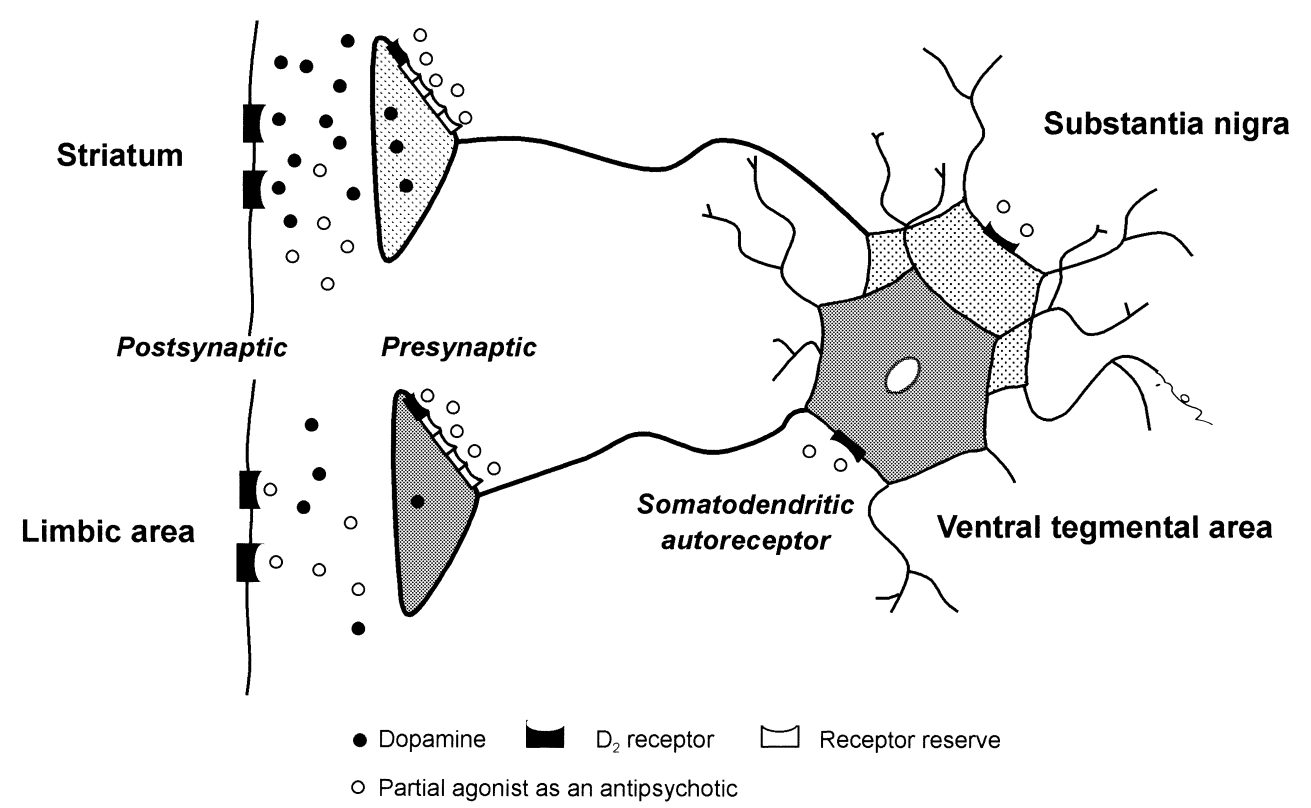

Fig. 1. A scheme describing the mode of action of the partial agonist as an ideal antipsychotic in the dopaminergic system in the brain. 


\section{Conclusion}

Partial agonists with adequate intrinsic efficacies and affinities for $\mathrm{D}_{2}$ receptors may be ideal antipsychotic drugs with potency to ameliorate schizophrenic symptoms and with reduced extrapyramidal and endocrinal side effects. It is suggested that the fine-tuning of the intrinsic efficacy and the affinity is an important strategy for defining an optimal antipsychotic based on the dopamine $\mathrm{D}_{2}$-receptor partial agonist concept. Such receptor partial agonists could offer a novel tool for modulation of dopaminergic transmitter systems in the CNS, the systems that are implicated most frequently in the pathogenesis of schizophrenia. Furthermore, the regulation of dopaminergic receptor subtypes other than $\mathrm{D}_{2}$ and the involvement of neuronal systems other than the dopaminergic system should be considered in therapy for schizophrenia, especially for the negative symptoms.

\section{Acknowledgments}

This work was supported in part by a Grant-in-Aid for Scientific research (B) from the Ministry of Education, Science, Sports and Culture of Japan (11694281).

\section{REFERENCES}

1 Seeman P, Lee T, Cau-Wong M and Wong K: Antipsychotic drug doses and neuroleptic/dopamine receptors. Nature 261, $717-719$ (1976)

2 Kane J, Hoingfeld G, Singer J, Meltzer H and Cozaril Collaborative Study Group: Clozapine for the treatment-resistant schizophrenic. Arch Gen Psychiatry 45, 789 - 796 (1988)

3 Lader MH: Neuroleptic-induced deficit syndrome (NIDS). J Clin Psychiatry 54, 493 - 500 (1993)

4 Gerlach J and Luhdorf K: The effect of L-dopa on young patients with simple schizophrenia treated with neuroleptic drugs. Psychopharmacologia (Berl) 44, 105 - 110 (1975)

5 Angrist B, Rotrosen J and Gershon S: Responses to apomorphine, amphetamine and neuroleptics in schizophrenic subjects. Psychopharmacology (Berl) 67, 31 - 38 (1980)

6 Van Tol HHM, Bunzow JR, Guan H-C, Sunahara RK, Seeman P, Niznik HB and Civelli O: Cloning of the gene for a human dopamine $\mathrm{D}_{4}$ receptor with high affinity for the antipsychotic clozapine. Nature 350, 610 - 614 (1991)

7 Lidow MS, Williams GV and Goldman-Rakic PS: The cerebral cortex: a case for a common site of action of antipsychotics. Trends Pharmacol Sci 19, 136 - 140 (1998)

8 Meltzer HY: Role of serotonin in the action of atypical antipsychotic drugs. Clin Neurosci 3, 64 - 75 (1995)

9 Riva MA, Tascedda F, Lovati E and Racagni G: Regulation of NMDA receptor subunit messenger RNA levels in the rat brain following acute and chronic exposure to antipsychotic drugs. Mol Brain Res 50, 136 - 142 (1997)

10 O'Dowd BF: Structure of dopamine receptors. J Neurochem 60, $804-816$ (1993)

11 Vallone D, Picetti R and Borrelli E: Structure and function of dopamine receptors. Neurosci Biobehav Rev 24, 125-132 (2000)
12 Giros B, Sokoloff P, Martres M-P, Riou J-F, Emoeine LJ and Schwarts J-C: Alternative splicing directs the expression of two $\mathrm{D}_{2}$ dopamine receptor isoforms. Nature 342, 923 - 926 (1989)

13 Monsma FJ Jr, McVittie LD, Gerfen CR, Mahan LC and Sibley DR: Multiple $\mathrm{D}_{2}$ dopamine receptors produced by alternative RNA splicing. Nature 342, 926 - 929 (1989)

14 Sokoloff P, Giros B, Martres M-P, Bouthenet M-L and Schwartz JC: Molecular cloning and characterization of a novel dopamine receptor $\left(D_{3}\right)$ as a target for neuroleptics. Nature 347, $146-151$ (1990)

15 Westerink BHC and de Vries JB: On the mechanism of neuroleptic induced increase in striatal dopamine release: brain dialysis provides direct evidence for mediation by autoreceptor localized on nerve terminals. Neurosci Lett 99, 197 - 202 (1989)

16 Koeltzow TE, Xu M, Cooper DC, Hu X-T, Tonegawa S, Wolf M and White FJ: Alterations in dopamine release but not doapmine autoreceptor function in dopamine $\mathrm{D}_{3}$ receptor mutant mice. J Neurosci 18, 2231 - 2238 (1998)

17 Dickinson SD, Sabeti J, Larson GA, Giardiona K, Rubinstein M, Kelly MA, Grandy DK, Low MJ, Gerhardt GA and Zahniser N: Dopamine $\mathrm{D}_{2}$ receptor-deficient mice exhibit decreased dopamine transporter function but no changes in dopamine release in dorsal striatum. J Neurochem 72, 148 - 156 (1999)

18 Benkert O, Muller-Siecheneder F and Wetzel H: Dopamine agonists in schizophrenia. Eur Neuropsychopharmacol 5, $43-$ 53 (1995)

19 Arnt J and Hyttel J: Postsynaptic dopamine agonistic effects of 3-PPP enantiomers revealed by bilateral 6-hydroxy-dopamine lesions and by chronic reserpine treatment in rats. J Neural Transm 60, 205 - 223 (1984)

20 Tamminga CA, Gotts MD, Thaker GK, Alphs LD and Foster NL: Dopamine agonist treatment of schizophrenia with $n$ propyl-norapomorphine. Arch Gen Psychiatry 43, 398-402 (1988)

21 Hoyer D and Boddeke HWGM: Partial agonists, full agonists, antagonists: dilemmas of definition. Trends Pharmacol Sci 14, $270-275(1993)$

22 Meller E, Enz A and Goldstein M: Absence of receptor reserve at striatal dopamine receptors regulating cholinergic neuronal activity. Eur J Pharmacol 155, 151 - 154 (1988)

23 Lawler CP, Prioleau C, Lewis MM, Mak C, Jiang D, Schetz JA, Gonzalez AM, Sibley AR and Mailman RB: Interactions of the novel antipsychotic aripiprazole (OPC-14597) with dopamine and serotonin receptor subtypes. Neuropsychopharmacology 20, 612 - 627 (1999)

24 Inoue A, Miki S, Seto M, Kikuchi T, Morita S, Ueda H, Misu Y and Nakata Y: Aripiprazole, a novel antipsychotic drug, inhibits quinpirole-evoked GTPase activity but does not up-regulate dopamine $\mathrm{D}_{2}$ receptor following repeated treatment in the rat striatum. Eur J Pharmacol 321, 105 - 111 (1997)

25 Inoue A, Seto M, Sugita S, Hide I, Hirose T, Koga N, Kikuchi $\mathrm{T}$ and Nakata $\mathrm{Y}$ : Differential effects on $\mathrm{D}_{2}$ dopamine receptor and prolactin gene expression by haloperidol and aripiprazole in the rat pituitary. Mol Brain Res 55, 285 - 292 (1998)

26 Inoue T, Domae M, Yamada K and Furukawa T: Effects of the novel antipsychotic agent 7-\{4-[4-(2,3-dichlorophenyl)-1-piperazinyl]butyloxy\}-3,4-dihydro-2(1H)-quinolinone (OPC-14597) on prolactin release from the rat anterior pituitary gland. J Pharmacol Exp Ther 277, 137 - 143 (1996) 